\title{
Elementos teóricos relativos al desarrollo comunitario local y a su práctica en la comunidad autónoma de Galicia
}

\author{
Xan Bouzada Fernández \\ Director del Instituto Gallego de Estudios Comunirarios \\ Universidad de Vigo. Departamento de Sociología. Vigo. Spain
}

\section{Resumen}

En primer lugar, tras constazar la reciente emergencia del sujeto local y las virtualidades y paradojas actualmente evidenciadas por el concepto de desarrollo local con raíces en la cultura y tradición del desarrollo comunirario, abordaremos algunos de los rasgos tipológicos - no solo los que impregnan contextos arcaicos y tradicionales, sino también aquellos de carácter moderno- que definen los modelos sociales comunitarios.

En segundo lugar, estableceremos algunas teorías relativas a la vinculación existente entre los procesos de desarrollo local, teniendo en ctenta las potencialidades inherentes al substrato socioterricorial y cultural en el cual éstos surgen, y la capacidad alternativa de los actores sociales para modificar la realidad.

Por último, concluiremos este artículo con una evaluación de cuatro experiencias acaecidas en contextos turales y las otras dos en medios urbanos. Escableceremos algunos criterios valorativos acerca de la vitalidad y solidez de éstos teniendo en cuenta los niveles de implicacion, asi como la riqueza y diversidad de los actores sociales implicados en el proceso.

Palabras clave: desarrollo local, actores, comunidad rutal, medio urbano.

\section{Abstract. Local community development in Galicia}

Firstly, after confirming the tecent emergence of the local actor and both the virtualities and paradoxes shown by the concept of Local Development rooted in Community Development culcura and tradition, we will deal with some of the typological features - those reaching not only archaic traditional contexts but also modern ones- which define community social patterns.

Secondly, we will present some theories about the connections between Local Development processes, taking into account the potentialities implied by the socio-territorial and cultural substrata in which they spring, and the innovating capacity of social actors to change reality.

Finally, we will conclude this article by evaluaring four different experiments: two of them rook place in rural contexts and the other rwo in urban ones. We will establish some evaluaring criteria about their vitality and reliability raking into accounc the levels of implication as well as the richness and diversity of the social actors involved in the process.

Key words: local development, social actors, rural community, urban milieu. 


\section{Sumario}

De la emergencia del sujeto local

Lo local y la comunidad como soportes y pretextos de desartollo

El desarrollo local y comunicario: virtualidades y paradojas

La transformación de las comunidades locales: de las comunidades rradicionales a las nuevas comunidades
El desarrollo local, entre la virtualidad endógena y la innovación

Remodelar o innovar

El desartollo local como una destreza social objetivadora de lo comunitario

Estimación evaluativa de cuatro experiencias de desarrollo comunitario $y$ local promovidas en Galicia

El concepto de desarrollo local y comunitario recubre hoy entre nosotros una serie de experiencias que tienen en común el presentarse como procesos concretos de organización del porvenir de ciertos territorios que, resultantes de los esfuerzos conjuntos de la población implicada, de sus representantes, de los agentes socioeconómicos y eventualmente de los agentes estatales, se encaminan a reconstruir un proyecto de desarrollo que integre diversos componentes económicos, sociales y culturales, así como actividades y recursos locales ${ }^{1}$. Abundando Paul Houée, el sociólogo bretón creador del concepto y promotor de la experiencia pionera de desarrollo local en la comarca de Le Mené, en que el objetivo de un comité de desarrollo local ha de ser el de favorecer el desarrollo global de la zona. Este desarrollo global ha de plantearse desde sus diversos aspectos económicos, sociales y culturales con la convicción de que éstos resultan inseparables y complementarios, así como merced a la participación intensa de su población y a la colaboración activa de todos los servicios competentes.

El ámbito de realización hoy de los proyectos de desarrollo local y comunitario, con independencia de las aparentes simplificaciones técnicas de que son objeto por parte de algunos programas, representa un sector pleno de sugererentes dificultades desde una perspectiva sociológica teórica.

El desarrollo local ha sido desde sus orígenes un ámbito en el que han convivido aspectos de tipo resistencial con aquellos otros de carácter alternativo. El desarrollo local ha, asimismo, oscilado frecuentemente entre la posible reformulación de lo endógeno y la apropiación de ideas externas en las cuales inspirarse. También ha caracterizado al desarrollo local y comunitario el hecho de que éste haya basculado entre aquellas propuestas que anhelaban la promoción de integrados limbos paternalistas y aquellas otras que (con decantada vocación democrática y participativa) apostaban por una reformulación comunitaria encaminada a facilitar modos de organización reticulados que uniesen a su eficacia económica y social su carácter democrático y parti-

1. Datar (1986). Guide du developpement local. París: Syrox: P. Houée (1986). "Dynamique du développement local rural's en VV.AA. Acteurs et actions de développement local. Saint Malo: College Coopérative de Bretagne, p. 41-71. 
cipativo. Alternancias todas ellas que acaso no resulten independientes del carácter de encrucijada social que hoy evidencian la mayor parte de las experiencias y proyectos sociales encuadrables bajo la rúbrica del desarrollo local y comunitario.

El desarrollo local y comunitario emerge hoy, a pesar de las diversas raíces en las que éste se sustenta, como un nuevo hecho social que aparentando venir a aportarnos una solución lo que viene a hacer realmente es a ponernos sobre el tapete toda una nueva y fecunda batería de problemas.

\section{De la emergencia del sujeto local}

La emergencia de lo local como un renacido sujeto social va a evidenciarse con una particular vitalidad hacia finales de la década de los setenta e inicios de los ochenta. Tras la crisis desencadenada en torno a los primeros años setenta se va a acudir al amparo de lo "micro", redescubriéndose al actor social y sus olvidadas virtualidades como medio para cambiar las condiciones de vida. Una ligera variación de perspectiva teórica será la que permita ese encuentro con el ámbito local y sus protagonistas.

Simultáneamente, lo local, frente al empuje inexorable de las potencias homogeneizadoras, inherentes al consumo y sus estéticas transnacionales, va a evidenciarse como soporte de lo "diferente" como un cuenco alternativo y resistencial que permitiese preservar las propias raices. Al mismo tiempo que las macrosolidaridades genéricas que habían inspirado a los movimientos sociales de los años sesenta y primeros setenta se fueron agostando, en lo local se sentían germinar nuevas formas concretas microsolidarias que se manifestaban como más factibles e inteligibles. Lo local, con su escala proxima y su complejidad social abarcable, tiende a configurarse como una nueva referencia ante una situación económica debilitada y generadora de paro, al tiempo que ante unos estados del bienestar que, agónicos, se aprestan a deslastrar viejos compromisos rejuveneciéndose con el recurso al alivio neoliberal ${ }^{2}$.

La aparición de nuevos agentes sociales en el seno de las comunidades caracterizados por unos mayores niveles de formación, empatía y capacidad en el manejo de la información, habituados en muchos casos a la movilidad, a la negociación y a la iniciativa social vendrían a aportar un especial impulso a aquellos proyectos de desarrollo económico y social que se decidian a echar sus anclas en el olvidado territorio local. Además de lo dicho, nuestro tiempo, definido en gran medida por la premura y la indeterminación, parece precisar del concurso de modelos utópicos de una escala manejable que permitan soportar el desplome de las ideas que habían servido de inspiración durante las pasadas décadas.

2. X. Greffe (1990). Descentralizar en favor del empleo. Madrid: Ministerio de Trabajo, p. 68 ys. 
En este contexto, el desarrolio local y comunitario parece resurgir como una utopía-refugio para tiempos de intenso desguace ideológico. El repliegue hacia lo local se produce en la forma de un nuevo ideal. Se quiso reforzar al estado y nacionalizar la economía cuando se confiaba en él. Áhora lo local y sus posibilidades de desarrollo, en opinión de algunos ${ }^{3}$, servirían de tierra de acogida al inevitable reenfoque tras la decepción. En el ámbito local, en fin, hallaron una nueva bandera étnica, ecológica y cultural muchos de los nuevos movimientos sociales que surgen al filo del cambio de siglo.

Aún así, durante los últimos años se ha evidenciado en el contexto europeo el empuje de las tendencias descentralizadoras, habría que decir que este tipo de procesos apuntan en ocasiones hacia la hipótesis de que nos pudiésemos hailar ante tácticas derivadas de las mismas lógicas del sistema, el cual preferirúa deslastrarse de algunos campos de gestión gravosos relegándolos hacia la periferia ${ }^{4}$. En este actualizado contexto el desarrollo local no va a emerger desde el vacío, sino que va a beber en toda una variopinta tradición que va desde la tradición de la economía social y el cooperativismo, hasta la animación sociocultural y la intervención socioeducativa, pasando por ámbitos de dinamización social tan sugerentes como el desarrollo comunitario anglosajón, el trabajo social reconceptualizado latinoamericano inspirado por Pablo Freire o la ordenación territorial francesa de los años setenta.

Toda esta rica tradición ha ido componiendo un sustrato fecundo que aunque no resulte siempre del todo visible no es totalmente ajeno a la actual eclosion del desarrollo comunitario y local. Las experiencia de desarrollo de comunidades que se promovieron en torno a la década de los años sesenta fueron portadoras de una relativa apertura, la cual facilitó el que éstas hayan intentado compaginar el objetivo de potenciar el tejido social existente con el aprovechamiento del empuje prescriptivo y transformador que se hallaba implícito en los modelos de planificación social de la comunidad. En estas experiencias se habia presentado como sustancial todo aquello que «estimulase y animase a la gente a expresar sus necesidades, la apoyase en sus acciones colectivas o les ayudase en sus proyectos"s.

De todos modos, en el desarrollo comunitario y local ha palpitado siempre un vigoroso aliento prometeico de vocación práctica frecuentemente inspirado desde fuera de la comunidad, dirigido a globalizar iniciativas que sirviesen para la mejora general de la calidad de vida de las colectividades en las que se promovia. También es cierto que en sus orígenes se hallaron asimismo estrategias que tendían a solapar problemáticas genuinamente sociales con discursos y retóricas de cariz moral. Desde el encomiable voluntarismo fundador de Charles

3. F. Plassard (1984). Autonomie au quotidien. Reponse à la crise? Rôle et sens des microinitiatives. Lyon: Chronique Social, p. 152.

4. P. Willmott (1989). Community Initiatives: Patterns and Prospects. Londres: Policy Studies Institute, p. 29.

5. A.D. Edwards \& D. Jones (1976). Community and Community Development. Paris: Mouton/The Hague, p. 138 y 141. 
Booth, pasando por el recreacionismo USA o la corriente antianómica de la animación sociocultural francesa hasta recientes trabajos de prevención criminológica comunitaria ${ }^{6}$, sigue perviviendo un flujo teórico integrador que sueña más con la construcción de un equilíbrio social plácido ajeno a conflictos disfuncionales que con la maduración ciudadana y la participación activa y crítica de los vecinos en la gestión de sus propios asuntos. Una utopía que, asumiendo la forma de una esperanza integradora germinada entre las clases medias, sigue hoy contando con una fuerte presencia entre aquellos que trabajan en el campo técnico-social.

En cualquier caso, en este tipo de prácticas, y tal y como lo entendieron algunos autores como Pablo Freire, la función de cambio social y de promoción democrática y popular no encontraría aquí las puertas completamente cerradas para el posible ejercicio de virtualidades transformadoras. En el caso concreto de Galicia, de la misma manera que aconteció en todo el Estado español ${ }^{7}$ durante los an̆os cincuenta y sesenta, nos mantuvimos bastante ajenos a este tipo de dinámicas. Hacia finales de esta última década se promovieron entre nosotros algunas experiencias inspiradas generalmente en el trabajo comunitario latinoamericano, las cuales hallaron frecuente acomodo en algunos programas de los servicios rurales de Extensión Agraria. Experiencias todas ellas que solían florecer merced al ejercicio voluntarista de algunos técnicos compelidos a actuar por propia iniciativa.

El desarrollo comunitario y local habría de llegar hasta nosorros con mayor fuerza, precisamente cuando el declive del marco macroindustrial puso a muchos hombres en la calle y cuando nuestras comunidades y sociedades locales hubiesen y experimentado una transformación crítica que las alejase de sus modelos tradicionales originarios.

\section{Lo local y la comunidad como soportes y pretextos de desarrollo}

Para la sociología el concepto de comunidad presenta un perfil polisémico y pleno de matices, el cual oscila entre la acepción histórico-genética y su utilidad para definir espacios y ámbitos territoriales concretos.

Entre los fundadores de la sociología Emile Durkheim y Ferdinand Tönnies ${ }^{8}$ realizaron un esfuerzo particular dirigido a desvelar sus significados. Aunque su perspectiva de análisis no siempre resultó convergente, sí se produjo una razonable coincidencia entre ellos al considerar ambos a la "comunidad" y a lo comunitario como una realidad enraizada en los albores de lo social y a la asociación o solidaridad orgánica como fenómenos prototípicos de la moderni-

6. T. Hopem \& M. Shaw (1988). Communities and Crime Reduction. Londres: Her Majesty's Stationnery Office.

7. Habría que anotar aquí a nivel del Estado algunos esfuerzos pioneros y en aquel momento poco apropiados, como el que ejemplificó el trabajo de Demetrio Casado con su «Plan Social Baza" en los años sesenta.

8. E. Durkheim (1982), La división del trabajo social. Madrid: Akal; F. Tönnies (1979). Comunidad y asociacion. Barcelona: Peninsula. 
dad. Para Durkheim la progresividad de la segunda con respecto a la primera parece establecerse de modo contundente.

Tönnies, por su parte, pareció dejar abierta una vía a la hipótesis de que la modernidad pudiese estar desalojando a la comunidad por su puerta principal para darle acogida desde la de servicio. Con posterioridad a ellos otros autores han seguido ahondando en una perspectiva dicotómica que evidencia todavía una considerable potencia explicativa. Si desde la sociologia, Talcott Parsons recuperó este enfoque para aplicarlo a su propuesta de las «variables de pauta ${ }^{9}$, en el ámbito de la antropología reaparece a menudo con ropajes diferentes y con vocación de recurrencia.

La matriz de acepciones en las que se inserta el término de "comunidad" invoca, no sólo su posible utilización para analizar y explicar algunos espacios sociales de pequeña escala, sino que también sirve como un recurso conceptual útil para allegarnos a la comunidad, y en general a lo comunitario, como un valor y un símbolo característico de nuestro imaginario culrural occidental ${ }^{10}$.

Desde Dutkheim y la escuela de Chicago la anomia y sus consecuencias sigue siendo un tema de preocupación que llega hasta nuestros días en la forma de un debate teórico que, tras ser inicialmente provocado por Duvignaud ${ }^{11}$, continúa hoy a través de la polémica latente que confronta en la escuela francesa actual los planteamientos de Gilles Lipovetsky y los de Michel Maffesoli. El recurso a la tentación comunitaria tiende hoy a suplir en muchas ocasiones el espacio carente y frágil provocado por el vacío social.

En este contexto, la comunidad y lo comunitario van a connotar una gama diversa de acepciones no siempre fácilmente delimitables entre las cuales las más evidentes serían las que siguen:

1. La comunidad como definidora de una etapa histórica anterior hoy superada por la sociedad moderna. Esta perspectiva tiende a percibir la comunidad como un hecho fundamentalmente residual.

2. La comunidad como un tipo de organización social tradicional aún vivo hoy, que se hallaría vinculado de modo prioritario a aquellos territorios sociales caracterizados por su tamaño reducido, por su ruralidad, así como por un relativo arcaísmo.

9. T. Parsons (1982). El sistema social Madrid: Alianza, p. 175 y s.; un caso reciente y original relativo a la antropologła es el que subyace en la obra de D.L. Clarke (1984). Argureologia analitica. Barcelona. Bellaterra. Quien distingue entre comunidades monotéticas y politéticas.

10. Tema este sobre el cual nos detuvimos en: X. Bouzada (1992). "Da comunidade ó desenvolvemento comunitarion. Revista de Economia Social e Cooperativismo, núm. 5, Vigo.

11. J. Duvignaud (1990). Herejta y subversión. Barcelona: Icaria; G. Lipovetsky (1986). La era del vacto. Sobre el individualismo contemporáneo. Barcelona: Anagrama. M. Maffesoli (1988). La temps des tribus. Le declin de lindividualisme dans les sociétes de masse. París: Meridiens; $M$. Bolle de Bal (1985). La tentation communitaire. Les paradoxes de la reliance et la contraculture. Bruselas: Université de Bruxelles. 
3. La comunidad como un modelo peculiar de organización de la socialidad que alcanza un determinado nivel de entidad territorial, relacional e identitaria con relativa independencia tanto de su configuración interna como del tipo de espacio en el que se halle implantado. Para este tipo de perspectiva las comunidades podrían resultar también detectables en áreas urbanas modernas, como puedan ser barrios o zonas diferenciadas.

4. La comunidad y lo comunitario como un hecho simbólico y social que es susceptible de poder impregnar toda una gama diversa de iniciativas y proyectos, los cuales añadirían a su carácter social su más preciso matiz comunitario. Este apartado abarcaría aquellos proyectos, colectivos y entidades a los que en algún momento se les denominó desde la sociología como "comunidades de interés".

5. En último lugar, incluiremos aquí una postrera posibilidad, en una gran medida relacionada con la anterior, que utiliza a la comunidad y a lo comunitario como pretextos potenciadores de los procesos de intervención y dinamización social. Esta utilización remite a la comunidad y a lo comunitario (o a lo local) desde una doble proyección; en un sentido el desarrollo declara aquí tener una vocación comunitaria, por desear ejercer sobre una comunidad constituida, mientras que en otro sentido esta perspectiva se encamina hacia el logro de modelos sociales que resulten más evolucionados y ricos en sus aspectos solidarios y comunitarios que los actualmente existentes.

La polisemia constatada, cuando no la ambivalencia del propio concepto, van sin duda a cooperar con su intensa proclividad a la paradoja.

\section{El desarrollo local y comunitario: virtualidades y paradojas}

En las lindes de lo social el desarrollo comunitario se debate contra sus propias paradojas. El desarrollo comunitario como vástago que es del flujo racionalizador experimentado por el trabajo social ha tenido que enfrentarse desde sus orígenes al hecho de que su éxito generador de progreso se fuese consumando al mismo tiempo que se producía la disolución de lo comunitario tradicional a expensas de lo orgánico y asociativo.

El poso comunitario ha actuado de feedback o como mínimo de pretexto para la ejecución de ese tránsito. Aquí lo informal comunitario ha servido de soporte a la desaparición de lo expresivo como centro y a su sustitución por la nueva centralidad instrumental y formal que caracteriza diferencialmente a los colectivos sociales más complejos y organizados. Como afirmaba Maciver ${ }^{12}$, es literalmente cierto que a la comunidad para poder salvarse no le queda más remedio que desaparecer.

12. R.M. Maciver (1917). Communiry: a Sociological Study. Londres; Macmillan and Co., p. 211. 
Resulta evidente que la paradoja de Maciver se instala de lleno en la ambigüedad polisémica del concepto de comunidad. No obstante, el desarrollo comunitario y local, al oscilar entre la aculturación modernizadora y el apoyo instrumental a las marginatizadas comunidades locales, avanza por un camino en el cual las fragilidades constatadas suelen actuar como estímulos para lograr nuevos impulsos y poder así acceder a medios y recursos más operativos. Quizás se esconde aquí en gran medida la misma paradoja con la que se han tenido que enfrentar diversas etrias y culturas al constatar que para poder defenderse se vefan obligadas a autodisolverse imitando a su agresor ${ }^{13}$.

Algo parecido le sucede al ciudadano que se halla ante el dilema de querer lo imposible al desear simultáneamente y en el mismo contexto social disfrutar de las virtualidades del desclasamiento sin asumir el rechazo del $e t h o s$ de su clase de procedencia. $O$, en su extremo contrario, al conservador que para no renunciar a sus privilegios se ve forzado a realizar concesiones hasta el punto de no poder evitar la pérdida de algunos de ellos ${ }^{14}$.

La tierra sobre la que se concreta el desarrollo comunitario y local acoge todo un haz de dinámicas paradójicas que condicionan la transparencia de sus procesos. El desarrollo comunitario nacido para favorecer la democratización de lo social y la participación se encuentra frente a la reiterada constatación de que quienes acuden a su convocatoria proceden con más frecuencia de la deseable de sectores sociales intensamente autoseleccionados. En el mejor de los casos: los más equipados de entre los precarios (A. Edward y otros, 1976: 174). Los agentes que lideran el proceso suelen seleccionarse aún en una mayor medida. El precario económico no sólo lo suele ser a ese nivel, también lo suele ser cultural y socialmente. Y precisamente lo cultural y lo social son las principales herramientas en la labor de desarrollo de las comunidades.

De este modo se ha instalado la sospecha de que el desarrollo comunitario y local y la descentralización hayan sido procesos que han favorecido de modo discriminatorio a las nuevas clases medias profesionales en vez de a las clases populares hacia las cuales éste decía dirigirse. De todos modos, los límites $y$ las formas de manifestarse este privilegio admitiría sin duda hoy algunas matizaciones. De la misma forma que acontece con las diferentes clases sociales tampoco todas las colectividades parten en igualdad de condiciones para hacer fructificar sus estrategias de desarrollo comunitario y local, aquéllas más dotadas técnica, cultural y socialmente dispondrán de mayores facilidades en el camino para que el proceso iniciado pueda llegar a buen término ${ }^{15}$.

El desarrollo comunitario y local es promovido con frecuencia en áreas y coyunturas sociales y económicas excesivamente frágiles. La economía social

13. A. Toynbee (1963). El mundo y el occidente. Madrid: Aguilar.

14. P. Burke (1991). La cultwa popular en la Europa modema. Madrid Alianza, p. 376. Paradoja del funcionalismo Barel.

15. En los trabajos: Empleo y educación a nivel local editado por el Ministerio de Trabajo en Madrid (1989) y G. Macrobie (1981). Small is possible. Londres: Jonathan Cape. Se muestran experiencias punteras en el desarrollo comunitario y local situadas en Canadá, Inglaterra y los Estados Unidos. 
suele potenciarse cuando la situación económica es menos favorable y allí donde las condiciones son menos propicias ${ }^{16}$, es decir, cuando y donde el capital privado no se atreve ${ }^{17}$. En estas condiciones resulta verosímil la duda de que a algún nivel el desarrollo comunitario y local pueda estar trabajando acríticamente a favor de la progresiva consolidación de una sociedad cada vez más dualizada. Una dualización que separaría a unos selectos operarios de bata blanca, empleados en competitivas industrias punteras, de aquellos otros trabajadores precarios del sector de la economía social. Nos hallamos asistiendo a un madurado proceso de desguace del estado del bienestar que podría utilizar el recurso al desarrollo local y comunitario en busca de un premeditado mecanismo previsor de tensiones es una hipótesis que resulta hoy pertinente a tenor de lo que acontece hoy en atgunos países.

Llegados a este punto resulta comprensible el hecho de que algunos autores se cuestionen el alcance y las posibilidades del desarrollo comunitario y local para erigirse en una "tercera vía" útil para resistir en el presente y adecuada para prefigurar un modelo social de futuro ${ }^{18}$. No obstante, el desarrollo comunitario y local, o por lo menos la sociedad civil popular en función y en base a la cual éste suele ser promovido, y tal como nos han mostrado algunos autores recientemente ${ }^{19}$, es también susceptible de ser percibido como un canal robusto para el aprovechamiento del potencial de la cultura popular en el rediseño de una sociedad más libre y solidaria. Potencial éste que resulta estratégico en épocas como la actual en la cual el bloqueo teórico y la desafección facilitan el que las medidas de carácter neoliberal sean presentadas como exclusivas e inexorables.

\section{La transformación de las comunidades locales: de las comunidades tradicionales a las nuevas comunidades}

La sociedad gallega vive actualmente un progresivo proceso de diversificación de sus comunidades que no resulta ajeno a la caracterización de las problemáticas, dilemas y modelos de racionalidad en las que se halla hoy implicadó el desarrollo comunitario y local. En virtud de este proceso, la situación actual de las colectividades comunitarias gallegas puede aproximarse a dos tipos idea-

16. Ejemplo contrario que muestra hasta donde puede llegar la promoción cooperativa cuando se produce en condiciones sociales, culturales y económicas favorables podría ser el caso del complejo industrial de Mondragón, en el País Vasco.

17. J. Robertson(1987). Furure work. Andershot-Hampshire: Gowe, p. 152: "Community businesses and community enterprises. This new approach to economic self-help in areas o high unemployement wich are unattractive to conventional profit-making busines". En La Voz de Galicia de 12-2-89 se indicaba: "Baja un $50 \%$ el ritmo de creación de sociedades anónimas laborales en Galicia [...] y España, al mismo tiempo que se producia un alza histótica de la bolsa españolan.

18. v. J. Robertson (1987), p. 153.

19. T. Radriguez Villasante (1991). "Movimiento ciudadano y iniciativas populates", (número monográfico de Cuadernos Hoac), núm. 16, Madrid; J. Arocena (1986). Le développement local. París: L'Harmattan. 
les que vamos a caracterizar utilizando una gradación dependiente de su nivel de tradicionalismo y que definiremos como $\mathrm{Cl}$ y $\mathrm{C} 2$.

El primer tipo, que incluye a aquellas comunidades con mayores adherencias tradicionales, resulta concretable en una serie de rasgos entre los cuales, y a efectos del tema que nos ocupa, podríamos resaltar los siguientes:

\section{Rasgos definidores de las CI}

\section{Relativos a las formas de poder instalado}

- Proclividad a la constitución de un poder único de tipo caciquil.

- La autoridad suele establecerse como una institución que rebasa el ámbito de lo político y se proyecta a largo plazo.

- La autoridad tiende a ejercerse con una doble caracterización expresiva e instrumental.

\section{Relativos al sistema social}

- El sistema social existente se muestra proclive al funcionamiento mecánico y turinario.

- El colectivo social se distingue por la escasa presencia de técnicos y mediadores.

- La capacidad de mediación y presión político-social es frágil y escasa.

- El nivel educativo y cultural, así como las posibilidades de promoción social son en general bajas.

- El desarrollo de la autonomía individual es limitado.

- Predomina la presencia de agentes sociales endoptoyectados con modos de implantación que privilegian las redes sociales locales.

- La organización del tejido asociativo se halla poco desarrollada.

- La conflictividad intralocal no genera cambio social y muestra una presencia azarosa y recurrente.

- Los recursos económicos y financieros susceptibles de ser movilizados para el desarrollo comunitario y local, así como su capacidad de gestión, suelen ser reducidos.

Este modelo de comunidad rural tradicional ${ }^{20}$ que presenta una densa y sugerente complejidad antropológica enraizada en las dificultades citadinas para comprender sus lógicas específicas permite allegarnos a un universo en el cual la precariedad y la escasez condicionan unos horizontes y unas expectativas limitadas. En este tipo de ámbitos la deuda y el rirualizado juego de favores que aproxima lo instrumental y lo expresivo, junto con la rigidez para asumir incruentamente los avances y mejoras en el vecino ${ }^{21}$ nos acercan a un universo activamente suspicaz y refractario al avance hacia lo desconocido. De igual modo, sus miembros se hallan poco equipados para conjurar el deslumbramiento y los consiguientes riesgos derivados de aquellas formas de consu-

20. Sobre esto véase el reciente y sugerente trabajo del profesor Eduardo Sevilla Guzmán (1991). "Hacia un desarrollo agro-ecológico desde el campesinado". Política y Sociedad núm. 9. Madrid, 57-72.

21. G.M. Foster (1988), Las culturas tradicionales y los cambios técnicos. México: Fondo de Cultura Económica, p. 48 y s. 
mo y de progreso que llegan hasta ellos. La dificultad para discernir ostentación y eficacia es en ocasiones una trampa mortal para la viabilización de estas frágiles economías.

Sobre las problemáticas que plantean las estrategias de desarrollo en este tipo de comunidades no nos detendremos aquí por existir una fecunda y relativamente conocida bibliografia sobre la materia ${ }^{22}$. Digamos simplemente que este tipo de cambio y con excesiva frecuencia las iniciativas que se promueven en su seno se caracterizan por su inconsistencia y precariedad ${ }^{23}$.

El segundo tipo de comunidad, o tipo $\mathrm{C} 2$, es aquel que se aproxima a la conformación de las comunidades de carácter urbano o barrial, así como también a las áreas más modernizadas de nuestro medio rural.

Entre sus rasgos destacariamos los siguientes:

\section{Rasgos definidores de las $C 2$}

\section{Relativos a las formas de poder instalado}

- Las formas de autoridad y de poder existentes están considerablemente diversificadas.

- La autoridad suele ejercerse con perspectivas de tiempo limitadas.

- Los modos de autoridad y de poder instalados tienden a manifestar un carácter fundamentalmente instrumental.

\section{Relativos al sistema social}

- El sistema social se halla diversiffcado y se complejiza orgánicamente.

- Su complejización y diversificación favorece la aparición de nuevos técnicos y mediadores.

- Su capacidad de mediación social y política es considerable.

- El nivel de autonomía individual de sus miembros aumenta respecto $2 \mathrm{Cl}$.

- Aumenta el número de agentes sociales que se hallan relacionados con redes sociales externas.

- El tejido asociativo es más rico que en $\mathrm{Cl}$.

- El conflicto intralocal es productivo y genera cambio social.

- Los recursos económicos y financieros, así como la capacidad de gestión, son relativamente fluidos.

El tipo de comunidad C2, al contrario de lo que sucede con la primera a la que nos referimos, tiende a confundirse con un estadio social propicio para la promoción de estrategias de desarrollo comunitario y local.

Las diferencias existentes entre esos dos tipos de colectividad afectan de manera particular a los modos característicos de ejercer sus miembros en el

22. Por su originalidad y fecundidad sigue siendo citable el trabajo de E. Fromm \& M. Maccoby (1973). Sociopsicoanálisis del campesino mejicano. México: Fondo de Culrura Económica; con respecto al caso gallego resulta de sumo interés el trabajo de R. Itura (1988). Antropología económica de Galicia. Santiago de Compostela: Xunta de Galicia.

23. A. Campos Beiro (1991). "Cooperativismo agrario en Galicia". Revista de Cooperativismo $e$ Economía Social, núm. 3, Vigo, p. 77-79. 
espacio público, constatándose una mayor destreza entre los segundos en el cultivo de las tácticas y dramaturgias requeridas por las relaciones sociales. Asimismo, resulta constatable que en lo referente al primer grupo diversas peculiaridades derivadas de su tradicionalidad tienden a restar capacidad empática y a limitar el alcance de las perspectivas de sus miembros. Mientras que en el primer tipo de comunidad el patriarcalismo tiende a favorecer el populismo ${ }^{24}$, en el segundo la fratría facilita la emergencia de potencialidades ciudadanas para el cambio y la democratización.

\section{El desarrollo local, entre la virtualidad endógena y la innovación}

Las comunidades de tipo $\mathrm{Cl}$ se nos presentan como espacios sociales en los cuales su carácter solidario-mecánico presiona a favor de la exclusiva receptividad de fórmulas que conecten y se entiendan con el sistema tradicional de funciones. Por su parte, aquellas del tipo C2 suelen mostrarse más abiertas a los ensayos innovadores, y esto quizás pueda ser debido a que ellas mismas no son sino un producto derivado del propio cambio ${ }^{25}$. Entre la primera y la segunda resulta crucial, a los efectos de estimar lo que es potenciador de lo endógeno o bien introductor de dinámicas innovadoras, el propio papel jugado en las $\mathrm{C} 1$ por el cacique, personaje funcional y redundante ${ }^{26}$, en contraposición con el rol y con las destrezas de los técnicos afectos al diseño de programas y a las prácticas planificadoras. Si bien en $\mathrm{Cl}$ la aparente proclividad funcional a capitalizar lo endógeno parece favorecer la maduración de dinámicas de desarrollo autosostenidas, también es cierto que las propias limitaciones en cuanto a la cantidad y calidad de sus agentes facilitará a menudo la incontenible irrupción de los modelos, recursos y valores externos.

Así acontece que el protagonismo de lo endógeno, allí y donde a éste se le supondria mayor capacidad operativa (debido a su mayor definición, y aun siendo más necesario ante la carencia de recursos y apoyos susceptibles de ser movilizados) suele ser menos factible, mientras que en aquellos otros ámbitos en los cuales resulta menos imprescindible es, sin embargo, más probable. De hecho, la reivindicación de lo autóctono como soporte y pretexto cultural e identitario suele producirse con mayor frecuencia en comunidades con un cierto nivel de modernización que en las de tipo tradicional. Este mismo y parad6jico desajuste entre actores, recursos y necesidades conduce a que donde las carencias y la marginalidad son más agudas el acceso a los apoyos y a los recursos financieros externos, a causa de una menor capacidad de mediación y presión, resulta asimismo ser menos frecuente.

Allí y donde el sistema tradicional ejerce su presión desde lo endógeno, éste puede condicionar las expectativas sociales instaurando un dominio de

24. T. Rodríguez Villasante (1990). "Teoría de redes de comporamiento". Salida, núm. 2, Madrid, p. 93-144.

25. M. Crozier y otros (1977). L'acteur et le système. París: Seuil. p. 338 y s.

26. J.L. Pintos (1990). Las fronteras del saber. Madrid: Akal. 
racionalidades limitadas. En estas comunidades la innovación suele provocar sospechas y reticencias, y cuando éstas son asumidas lo hacen desde la tension y la crisis de lo que irrumpe desvertebrando sin llegar a establecer un pacto con las lógicas y racionalidades preexistentes. El proceso en virtud del cual una zona de agricultura minifundista de baja productividad como es la gallega llegó a acumular un parque de tractores excesivo e infrautilizado tiene mucho que ver con la frágil bulimia de bienes posicionales que puede ser artificiosamente provocada por el mercado en el seno de una comunidad tradicional relativamente inerme ${ }^{27}$ ante el empuje del imaginario consumista.

En una dirección parecida puede ser también constatado que es precisamente en $\mathrm{Cl}$, en donde la cooperación mutua y la predisposición para generar redes de iniciativa resultaría más precisa, el ámbito en el cual éstas suelen tener una menor presencia ${ }^{28}$. Por su parte en las $\mathrm{C} 2$ lo endógeno es frecuentemente utilizado, cuando no inventado y construido, como un pretexto de fuerte vocación instrumental encaminado a favorecer logros sociales y políticos preconcebidos. Es por esto que en este tipo de contextos las propuestas de cambio susceptibles de promover nuevos roles y dinámicas sociales tienden a emerger con mayor vitalidad y fluidez.

\section{Remodelar o innovar}

Desde la antropologfa social ha venido siendo aceptado el hecho de que la comunidad tradicional tendía a evolucionar a partir de aquel mismo juego de equilibrios sobre el que ésta inicialmente se sustentaba ${ }^{29}$. A pesar de esta recurrencia, recientemente John Elster ${ }^{30}$ ha liamado la atención sobre el hecho de que el posible equilibrio funcional que presuponiamos a las sociedades agrarias tradicionales pudiese ocultar un efecto de ilusión debido a la visión limitada del observador o incluso al efecto de la ideología local.

Retomando de nuevo la intuición de Maciver, conviene incidir en que la propuesta subyacente al desarrollo comunitario y local se aproxima mucho a una orden contradictoria empeñada en el objetivo aparentemente imposible de preservar lo comunitario disolviendo simultáneamente la comunidad. Aproximándonos a aquellos posicionamientos técricos que al situarse en una posición externa parecen reconocer implicitamente la virtual imposiblidad de un proyecto exclusivamente endógeno y la necesidad de recurrir a racionalidades externas que actuen codiseñando y promoviendo el cambio en la comunidad. Sabemos no obstante que los cambios, incluso los radicales, son posibles desde el sistema subyacente aunque éstos se produzcan bajo una serie

27. J. Elster (1988), p. 44 .

28. Ch.J. Erasmus (1954). "An Anthropological views rechnical assistancew. The Scientific Montbly, núm, 78, p. 147-158.

29. G. Balandier (1971). Sens et puissance, les dynamiques sociales. Paris: PUF, p. 225-230; sobre el mismo rema: G.M. Foster (1988), p. 25.

30. J. Elster (1990). El cambio tecnologico. Barcelona: Gedisa. p. 60. 
de circunstancias tan heterogéneas como aquéllas oscilantes entre el estig$\mathrm{ma}^{31}$, el azar o el efecto de complejos procesos de remodelación cultural desencadenables desde las estructuras existentes.

Lo que sí ha sido recurrentemente defendido desde diferentes ópticas es el hecho de que las probabilidades de desarrollo comunitario y local se incrementan en aquellos ámbitos a los cuales les asiste una fuerte y consolidada voluntad por definirse desde una cultura y una identidad local específica. Esta cultura e identidad específicas asumidas van a facilitar el mantenimiento y la diversificación de las dinámicas de cambio ${ }^{32}$. Este reconocimiento representa, en nuestra opinión, no sólo un dato cualitativo de carácter genérico, sino también la constatación derivada de que allí donde la identidad es asumida como un dato objetivo, la autoconciencia identitaria puede actuar de soporte para un proyecto local que habiendo sido asumido por el colectivo es susceptible de ser concretado en una acción planificada. En este sentido pensamos deben se interpretados los tempranos posicionamientos de autores como Carolyn $\mathrm{F}$ Ware ${ }^{33}$, quien constató pronto que los procesos de autoinvestigación pueden resultar una vía fecunda para la organización futura de la comunidad. Promover la autoconciencia ha sido precisamente el método reiteradamente recomendado por Pablo Freire. La importancia y trascendencia del modelo mediante el cual la sociedad es capaz de leerse a sí misma ha sido algo que también Touraine entendió como un dato estratégico para el cambio y la transformación social ${ }^{34}$.

El "aprendizaje colectivo" supondría para Crozier una condición inexcusable del cambio social transformador. Más recientemente Chombart de Lauwe reconocia que es precisamente en el momento en el cual los individuos y los gru-

31. El intento de explicar el desarrollo japonés ha supuesto durante los últimos años el despliegue de una fecunda batería de análisis en su mayor parte de inspiración Weberiana, entre los cuales conviven las perspectivas remodeladoras con la supuesta capacidad reactiva del estigma social para actuar como causa desencadenante de progreso socioeconómico. Quizás no resulte tampoco azaroso el hecho de que el pueblo andaluz de Lepe, el más vilipendiado por el humor satírico iberico, sea hoy un brillante ejemplo de desarrollo local (véase El Pats de las Ciudades de 23-5-90). Azaroso si que parece haber sido el origen del actual florecimiento turístico y económico del pueblo aragonés de Plan conocido por el inesperado impacto mediático logrado tras la organización de una famosa kcaravana de mujeres" al estilo Hollywood.

32. A.Vázquez Barquero (1988). Desarrollo local. Madrid: Pirámide, p. 58 y 90 ; así como P. Houee (1974). Quel avenir pour les ruraux. París: Les Editions Ouvrières. Nosotros mismos renemos incidido sobre esto: X. Bouzada (1991). uIdentidade e cultura no desenvolvemento locals. Revista de Economia Sociale Cooperativismo, núm. 3, Vigo, p. 133-139.

33. C.F. Ware es uno de los autores fundadores de la sociología de la comunidad, suyo es el estudio "Greenwich Village 1920-1930", realizado en 1935 y editado en Boston por Houghron Mifflin, quien más tarde en riempos de la Alianza para el Progreso se dedicó a la aplicación de sus conocimientos para la práctica del desarrolio de las comunidades. Así su obra: Estudios de la comunidad (1986 e. o. 1963). Buenos Aires: Humanitas.

34. A. Touraine (1973). Production de la société. París: Seuil. p. 28-30; M. Crozier y otros (1977), p. 34I; P.H. Chombart de Lauwe (1988). Culture-action dos groupes dominés. Rapports à l'espace et developpement local. París: L'Harmattan, p. 23. 
pos se percatan de su siruación y de sus posibilidades cuando éstos pueden llegar a instrumentalizar y a movilizar posibilidades técnicas nuevas para producir y conducir esos procesos.

En este sentido resulta pertinente traer aquí a colación la reflexión de Elster ${ }^{35}$ cuando pone en relación la dinámica del cambio con la facultad para transformar nuestros propios criterios de adaptación. No obstante, este sesgo presupone la capacidad del colectivo para realizar un doble juego en virtud del cual la intervención sobre el sistema supone la capacidad para instituir un doble de lo real ${ }^{36}$. Este recurso resul raría manipulable y permitiría establecer la relación con el sistema social existente como un dato añadido con vistas a lograr la máxima economía de medios y la optimización de los resultados previsibles $^{37}$.

El posible recurso al desdoblamiento por parte de las comunidades es quizás uno de los factores que pueden explicar el optimismo antropológico de Levi-Strauss cuando afirmaba que la humanidad es una rica poseedora de posibilidades imprevistas y que el progreso no se produce necesariamente en base a la imagen excesiva y confortable de una simple "similitud mejorada", $y$ que bien al contrario esta está llena de potencialidades de aventura y ruptura ${ }^{38}$.

\section{El desarrollo local como una destreza social objetivadora de lo comunitario}

En aquellos contextos y ámbitos sociales en los cuales lo endógeno tiende al mantenimiento de una autorreferencialidad bloqueada, el desarrollo comunitario y local se halla condenado a la ineficacia y a la precariedad. Por el contrario, allí y donde lo local se concibe a sí mismo desde la mareria abstracta del soporte técnico, la comunidad es susceptible de poder iniciar y conducir desde ella misma los procesos de transformación y cambio planificados. Casos urbanos en Galicia, como el del barrio de Caranza en la ciudad de Ferrol o el de Casco Vello en la de Vigo, pudieron ponerse en marcha a partir del momento en el que la comunidad fue capaz de autocontemplarse con una mirada exterior a sí misma que le permitiese reaccionar activamente convirtiendo en un plan de desarrollo comunitario configurador de nuevos modos de gestión y relación social lo que hasta ese momento había sido percibido como un azaroso e inexorable problema de convivencia.

Aquí la autoconciencia precedió al autodiagnóstico y éste, a su vez, al proyecto de acción comunitaria. En el caso de experiencias de desarrollo en medios rurales de Galicia, como el del Baixo Miño o el del Concello de Vílardevós, la tealización de la experiencia resulta inseparable de la presencia de agentes

35. J. Elster (1990), p. 60.

36. C. Rosset (1984), Le réel et son double. París: Gallimard.

37. M. Crozier y otros (1977), p. 355 y 343.

38. C. Levi-Strauss (1968). Race et histoire. Paris: Mediations, p. 84; R. Axelrod (1986). La evolución de la cooperacion. Madrid: Alianza, p. 32. 
externos que van a ser en gran medida los que hagan posible el tránsito desde la comunidad implícita hacia el desarrollo explícito de sus potencialidades. En estos dos casos ha coincidido una matriz diversa de factores que hallaron un espacio propicio de convergencia en el mismo desarrollo del plan. Desde la presencia de activos actores institucionales y públicos, o de algunos miembros de la comunidad que se habían hallado implicados en experiencias sociales y organizativas con un cierto nivel de complejidad, hasta la cardinal participación de agentes sociales de procedencia externa capaces de asumir la función de gestión y programación, al lado de una situación cultural y social favorable, puede todo elio ayudarnos a entender la actual maduración de este tipo de experiencias.

El poder de inventar realidades que algunos autores habian visto en su momento como un peligroso virtuosismo de técnicos y planificadores ${ }^{39}$, emerge así como una estrategia efectiva que ha sido producida a través de una premeditada elaboración. Una estrategia, ésta, que podrá ser viable siempre y cuando la comunidad logre distanciarse de sí misma lo suficiente para así poder hurgar de modo desdramatizado en la intrincada complejidad de sus propias vetas sociales ${ }^{40}$.

Detenernos hoy a reflexionar acerca de las lógicas y racionalidades sociales subyacentes a los procesos de desarrollo comunitario y local puede ser un modo de caminar hacia un mejor conocimiento de las virtualidades latentes en aquéllos procesos sociales de descentralización que pueden ser susceptibles de promover la dinamización social y la democratización participativa en ámbitos comunitarios $y$ locales.

\section{Estimación evaluativa de cuatro experiencias}

\section{de desarrollo comunitario y local promovidas en Galicia}

Las cuatro experiencias en las que nos detendremos será en aquellas a las que ya nos hemos referido en el apartado anterior: las de los barrios de Caranza en Ferrol y Casco Vello en Vigo, así como las llevadas a cabo en las áreas de Vilardevós en Ourense y la comarca del Baixo Miño en Pontevedra.

La experiencia de desarrollo local del baixo Miño afecta a una zona siruada entre el río Miño y la costa Atlántica que dispone de una población aproximada de 45.000 habitantes, de los cuales el $75 \%$ residen en zonas rurales y se reparten en cinco ayuntamientos diferentes. En el Baixo Miño se puso en funcionamiento en 1989 un módulo de desarrollo tocal dentro de una escuela taller, el cual desembocó en la actualidad, merced al acierto y empuje de algunos de sus componentes, en uno de los cuatro programas "Leader" que se van a llevar a cabo próximamente en Galicia.

39. G.M. Foster (1988) p. 215.

40. En esta línea son de indudable relevancia los trabajos de: M. Mormont (1989). "Le local convié au développement". $R I A C, 22 / 62$. Montréal, p. 151-163; asi como el de A. Micoud (1989). uLe développement local ou comment construire de nouveaux territoiresn. RJAC, 22/62, Montreal, p. 33-38. 
Esta zona contaba con una tradición relativamente activa en iniciativas comunitarias a pesar de que nunca había contado con apoyos excesivos por parte de la Administración. Experiencias anteriores como la Granxa Escuela de Budiño y el complejo de Louro o la frustrada iniciativa de Cobami (Cooperativas do Baixo Miño) o el desarrollo hortícola cooperativo de O Rosal en los 1960-1970; o la más reciente vitalidad sociocomunitaria de la Parroquia de Pexegueiro en Tui, son algunos ejemplos reseñables de iniciativas endógenas promovidas en una zona de considerable vitalidad social. El módulo de desarrollo local y el programa Leader fueron recibidos en la zona con satisfacción al tratarse de un inesperado apoyo por parte de instituciones a unas comunidades que, a pesar de las dificultades existentes, no se habían mantenido totalmente pasivas.

La experiencia desarrollada en los municipios orensanos de Vilardevós y Castrelo do Val, situados en el interior de la provincia de Ourense, implica a una población aproximada de 6.000 habitantes que residen en un área rural interior alejada de los grandes núcleos, la cual se vio muy afectada por las corrientes emigratorias de los años sesenta y setenta. Esta zona caracterizada por sus rasgos tradicionales iba a ver en el año 1969 como se iniciaba un proceso de desarrollo comunitario inspirado y animado por dos curas rurales postconciliares que intentaron avivar las brasas que aún quedaban de una cierta sensibilidad cívica y comunitaria con sus raíces en la Segunda República.

Entre los años 1972-1977 se produjo un parón, siendo durante ese último año cuando íba a llegar a la zona el actual promotor y también cura párroco y concejal Digno González, quién ha venido promoviendo una dilatada serie de iniciativas estimuladas por sus relaciones exteriores, primero con las escuelas rurales familiares y hoy merced a su integración en el COFEDER que, con sede en Valladolid, agrupa a diecisiete centros de desarrollo rural, así como en virtud también de su vinculación a la red rural de preescolar na Casa.

El colectivo Portas Abertas desde el que se coordina y promueve el trabajo comunitario en estos dos municipios orensanos ha desarrollado un programa de actividades dirigido a la infancia, mujeres y a la tercera edad con una rigurosa y costosa estructura descentralizada que ha respetado a los principales núcleos de la zona.

Para esta experiencia sus promotores contaron durante los tres últimos años con ayudas del' Ministerio de Asuntos Sociales por un importe medio de diez millones de pesetas al año, a los cuales han sabido extraer un excepcional rendimienro. En la actualidad han conseguido un fondo de ayuda del programa "Leader» que les permirirá abordar proyectos de desarrollo económico local en sectores como la agriculrura (castaña y miel), el turismo rural (caza) y el apoyo a una pequeña empresa cooperativa existente en la zona.

El barrio de Caranza en El Ferrol tiene una población aproximada de 20.000 personas y en él se dan todas la condiciones críticas que han afectado a nuestros barrios obreros desde mediados de los años setenta. El paro y la droga, sobre todo entre los jóvenes, acentuaron una profunda crisis social en esta 
comunidad urbana que había vivido solidaria y combativamente durante los primeros años setenta.

La situación creada a mediados de los ochenta condujo a la asociación de vecinos al empeño de poner en marcha un plan comunitario. A partir de 1987 y con el problema de la droga y la marginalización de la juventud como espoleta, el plan ha ido avanzando hacia su consolidación. En la actualidad dispone de un presupuesto de veintiún millones anuales que le permiten desarrollar un intensivo y variado conjunto de actividades fundamentalmente dirigidas a la juventud y a la mujer, que van desde el programa de deportes hasta el taller de música o las actividades de tipo formativo.

El barrio del Casco Vello de Vigo, con una población en torno a los 4.000 habitantes, se halla situado en el centro de la ciudad y adolece de los problemas característicos de este tipo de zonas, los cuales se resumen en el hecho de que desde hace quince afios éste experimenta un progresivo deterioro urbanístico y social. En el barrio se fundó durante el año 1972 una asociación de vecinos que al distinguirse por su vigor reivindicativo acabó por convertirse en una institución sumamente incómoda para los gobiernos municipales de este período. Los últimos años de corporación democrática que habrían podido marcar un cambio de rumbo hacia formas ciudadanas más pragmáticas y participativas vieron truncado este objetivo en gran medida debido a la falta de sensibilidad evidenciada en este terreno por parte de los recientes responsables municipales. Un cambio de perspectiva en la línea de trabajo de la asociación parecía resultar imprescindible si se deseaba dar una respuesta con visos de eficacia a los problemas de deterioro urbanístico y social que afectan actualmente al barrio. Será a finales del año 1991 cuando la convergencia de diferentes factores favorables facilite el que se inicie con entusiasmo un serie de iniciativas para poner en marcha un plan comunitario que contaría con el asesoramiento de aquél que había sido puesto en marcha anteriormente en el barrio ferrolano de Caranza.

De cara a realizar una aproximación evaluativa acerca de la solidez comunitaria de las cuatro experiencias seleccionadas, hemos elaborado un esquema en base a diez indicadores que permiten tanto el establecimiento de una evaluación global al ser leídos conjuntamente como la introducción de elementos de comparación y de contraste entre ellas. La presencia de líderes carismáticos ha sido resaltada de modo recurrente como una de las condiciones que facilitan el arraigo social de los proyectos comunitarios, no obstante esta presencia suele ser poco consistente en aquellas experiencias que han sido diseñadas desde arriba y a partir de criterios fundamentalmente técnicos, como sucedió en su caso con el proyecto del Baixo Miño. El barrio de Caranza, por su parte, ha visto durante los últimos años como se iban alejando algunos de los viejos líderes vecinales, a veces por tensiones y cansancio, otras por la dificultad de mantener un diálogo estable entre el maduro sindicalista y el joven técnico que en muchos casos se manejan con imaginarios ostensiblemente diferentes.

El segundo punto se halla en gran medida relacionado con el anterior. En el caso del Baixo Miño diferentes agentes sociales se han ido aproximando a 
los técnicos del módulo de desarrollo local, y hoy el centro de desarrollo rural, con el objetivo de buscar apoyo para sus proyectos e iniciativas.

El punto tercero aparece relativamente consolidado y claro en el Baixo Miño y en el barrio de Caranza. Por su parte, en Vilardevós la presencia de personas como el cura de Arzádegos, D. Digno, ejemplo de líder carismático y de persona entusiasta y bien informada, hace que las funciones de coordinación aparezcan bien cubiertas siendo recabada la presencia de técnicos para la elaboración de los informes y proyectos agrarios y laborales o como profesionales en las actividades de tipo educativo. En el Casco Velio de Vigo la escasa consolidación de los roles técnicos deriva básicamente de las actuales dificultades financieras. Y esta dificultad será la que explique también las diferencias internas existentes en los puntos cuarto y quinto.

El sexto indicador nos muestra como el módulo y el posterior "Leader" Baixo Miño, al haber sido percibido como un logro «a mayores" por parte de

Tabla I. Decálogo evaluador de experiencias comunitarias. modo satisfactorio; objetivo medianamente cumplido; $\square$ objerivo sin alcanzar.

\begin{tabular}{|c|c|c|c|c|}
\hline & Baixo Miño & Vilardevós & Casco Vello & Caranza \\
\hline $\begin{array}{l}\text { Presencia de líderes } \\
\text { carismáticos }\end{array}$ & $\square$ & m & $\mathbf{n}$ & - \\
\hline $\begin{array}{l}\text { Presencia de personas } \\
\text { con experiencia en } \\
\text { el movimiento social }\end{array}$ & - & a & घ & a \\
\hline $\begin{array}{l}\text { Existencia de un staff } \\
\text { profesional }\end{array}$ & a & घ & घ & घ \\
\hline $\begin{array}{l}\text { Disponibilidad de un flujo } \\
\text { de fondos estable }\end{array}$ & a & घ & घ & a \\
\hline $\begin{array}{l}\text { Disponibilidad de } \\
\text { un local propio }\end{array}$ & w & घ & 口 & च \\
\hline $\begin{array}{l}\text { Existencia de simpatías } \\
\text { hacia el proyecto entre } \\
\text { politicos y funcionarios }\end{array}$ & (a & घ & m & m \\
\hline $\begin{array}{l}\text { Capacidad para mantenerse } \\
\text { en equilibrio frente al poder } \\
\text { de los políticos locales }\end{array}$ & ш & घ & D & $\mathbf{\theta}$ \\
\hline $\begin{array}{l}\text { Lograt corresponsabilizat } \\
\text { a los participantes y a } \\
\text { la comunidad, así como } \\
\text { a los que apoyan y financian }\end{array}$ & n & घ & $\mathbf{n}$ & घ \\
\hline Gestión financiera escrupulosa & m & घ & - & $\boldsymbol{\square}$ \\
\hline $\begin{array}{l}\text { Tener capacidad para } \\
\text { acoger a nuevas personas } \\
\text { y a nuevas ideas }\end{array}$ & E & घ & घ & घ \\
\hline
\end{tabular}


los ayuntamientos de la zona, y al concebirlo éstos como un recurso genérico de favorable incidencia electoral, ha sido, en casi todos los casos (Tui, Tomiño, O Rosal, Oia), muy bien recibido.

El proyecto de Vilardevós, por su parte, disfruta hoy de un apoyo claro aunque sesgado políticamente. En el barrio de Caranza y debido a una actual polarización de intereses políticos entre el ayuntamiento de Ferrol - con gobierno de izquierdas - y el Plan Auronómico de Drogodependencias dependiente de la Xunta, se halla en una situación de cierta tensión que parece no ser ajena en este caso a la dificultad de algunos concejales para discernir entre lo social, lo técrico y lo político.

El séptimo indicador nos pone de manifresto hasta qué punto resulta costoso en ocasiones mantener la, por otro lado necesaria, autonomía poítica de las iniciativas comunitarias. El proyecto más autónomo, Casco Vello, es el que se halla en una situación financiera más precaria.

Los proyectos comunitarios parecen todos ellos tener, por el hecho de serlo, una cierta capacidad para lograr corrientes favorables de reconocimiento. No obstante, asimismo todos ellos, tienen también ciaras dificultades para conseguir que comunidad y responsables políticos se vuelquen sin reparos en su apoyo.

Si bien la gestión de los recursos financieros suele ser generalmente rigurosa, hay que reconocer un mayor talón de Aquiles a nuestro movimiento de D. C. y L. en lo que se refiere a su capacidad de conseguir atraer a nuevos recursos humanos que actualicen sus potencialidades de transformación.

Si nos detenemos brevemente a tomar en consideración globalmente cada una de las experiencias, podemos comprobar como la primera de ellas evidencia un cariz claramente gestionista ${ }^{41}$, mientras que la segunda es probablemente aquélla que, optimizando las potencialidades de una zona rural tradicional, logra de manera bastante consistente aproximarse al ideal de un proyecro maduro de desarrolio de comunidad participativa.

En el caso del Casco Vello, la juventud del proyecto y las reservas que produce anre ciertos políticos el tener como interlocutora a una asociación con una clara tradición reivindicativa y beligerante acaso ayuden a entender su inspiración simultáneamente comunitaria y ciudadana, al tiempo que financieramente precaria.

En el barrio de Caranza y en parte debido a su carácter de pioneros y de la dificultad existente para mantener un diálogo fluido y un reparto de protagonismo entre técnicos, líderes asociativos y políticos, parece, a pesar de haber nacido con un fuerte impulso ciudadanista, irse deslizando hoy hacia un modelo cada vez más gestionista.

41. Remitimos aquí al lector al sugerente trabajo de T. Rodríguez Villasante y ortos (1990). "Asociativa ciudadana. Textos sobre asociacionismo de Madrid". Monográfico revista Salida. Madrid: Facmum. 